\title{
Experimental study of repair mixtures as glues for connecting elastomers with metals
}

\author{
Anatoliy Ishchenko ${ }^{1}$, Viktor Artiukh ${ }^{2, *}$ and Vladlen Mazur ${ }^{3}$ Sergey Poberezhskii ${ }^{4}$ and \\ Maxim Aleksandrovskiy ${ }^{5}$ \\ ${ }^{1}$ Pryazovskyi State Technical University, Universytets'ka, 7, Mariupol, 87500, Ukraine \\ ${ }^{2}$ Peter the Great St. Petersburg Polytechnic University, Polytechnicheskaya, 29, St. Petersburg, \\ 195251, Russia \\ ${ }^{3}$ LLC 'Saint-Petersburg Electrotechnical Company', Pushkin, Parkovaya, 56, Saint-Petersburg, \\ 196603, Russia \\ ${ }^{4}$ Moscow Aviation Institute, Volokolamskoe highway, 4, Moscow, 125993, Russia \\ ${ }^{5}$ Moscow State University of Civil Engineering, Yaroslavskoye shosse, 26, Moscow, \\ 129337, Russia
}

\begin{abstract}
Experimental study of strength of glued connections where repair mixtures Diagum FL, Diagum P and Diaflex are used is shown. Suggestions of each repair mixture use are given. Obtained results provide developing of durable and economical technical solutions: shear shock absorbers, elastic couplings, elastic shafts with high energy intensity which in some cases allow to avoid failures of metallurgical equipment under dynamic loading. In addition, use of repair mixtures with elastomers helps to make durable coatings of steel surfaces.
\end{abstract}

\section{Introduction}

Elastomers are increasingly used in metallurgical engineering. These are different elastic elements made from rubber and polyurethane installed in steel assemblies, namely, buffers, shock absorbers, elastic shafts and couplings, protectors for protection of metallurgical equipment against accidental breakdowns, etc. [1-5].

Another group of devices and details have elastomers as coatings of steel surfaces that prevent premature abrasive wear of covered surfaces, these are sieves of screens, outer surfaces of rollers for removing liquid from surfaces of metal strip, inner surface of mills drum, outer surfaces of rollers for transporting cold rolled products, etc.

For all above mentioned devices and details [6-8] elastomer layer must be firmly connected to metal surface. Strength, rigidity and durability of combined detail or device depend on strength of connection between elastomer and metal $[9,10]$.

There are hot and cold methods (two main processes) of connecting elastomers with metal [11-17]. Hot involves connecting elastomer and metal by means of vulcanization that is laborious: firstly, metal surfaces that will be connected to elastomers are coated with layer of brass or ebonite and finally, these metal surfaces are vulcanized with rubber. Connection

* Corresponding author: artiukh@mail.ru 
strength corresponds to strength of rubber. Another method (the most common one) is usage of glue known as Leikonat. Connecting technology is rather complicated and expensive, shear strength of connection is $\tau=3 \ldots 5 \mathrm{MPa}$.

Simpler and cheaper method is cold method when finished details made from metal and elastomer are connected. This method is more versatile but has limitations in size and shape of details to be connected; however, it gives less durable connection. The most widely used glue 88 -H gives connection strength $\tau \approx 1 \ldots 2 \mathrm{MPa}$ that is much less than required strength. The latter circumstance significantly limits application scope of rubber-metal details made by the cold method.

At the same time, practice requires a simple and reliable method of connecting elastomers to metals because application scope of elastomers is expanding continuously. For example, usage of high-strength polyurethane elastomers for increase of metallurgical equipment durability has increased several times over last 10 years.

For more complete use of properties of high-strength elastomers it is necessary to achieve strength of elastomer-metal connection not lower than $10 \ldots 12 \mathrm{MPa}$ which is significantly greater than strength provided by glue $88-\mathrm{H}$. Specialists from department Mechanical equipment of metallurgical plants of Pryazovskyi State Technical University (PSTU, Ukraine) and from department Hydraulics and Strength of Peter the Great St. Petersburg Polytechnic University (SPbPU, Russian Federation) performed experimental study of applicability of repair mixtures Diagum FL, Diagum P and Diaflex as cold curing glues for connecting polyurethane elements with steel details.

The strongest structural polyurethanes among elastomers such as Adiprene L-167 and Adiprene L-100 were tested. The main mechanical characteristics of these elastomers are given in Table 1. Purposes of these elastomers are coating of metal surfaces to reduce abrasive wear, manufacture of elastic elements, buffers, shock absorbers and safety devices $[18,19]$.

Repair mixtures Diagum FL, Diagum $\mathrm{P}$ and Diaflex are two-component elastomers polymerization of which can occur both at high $\left(\mathrm{t}=40 \ldots 60^{\circ} \mathrm{C}\right)$ and normal $\left(\mathrm{t}=10 \ldots 20^{\circ} \mathrm{C}\right)$ temperatures and it does not require to create high pressure [20]. Their mechanical characteristics are shown in Table 2 .

Table 1. Mechanical characteristics of polyurethane elastomers.

\begin{tabular}{|l|c|c|}
\hline \multirow{2}{*}{\multicolumn{1}{|c|}{ Materials characteristics }} & \multicolumn{2}{|c|}{ Elastomer } \\
\cline { 2 - 3 } & Adiprene L-167 & Adiprene L-100 \\
\hline Tensile strength at break, MPa & 50 & 35 \\
\hline Modulus of elasticity at tensile (100\%), MPa & 14 & 7.6 \\
\hline Modulus of elasticity at compression, MPa & 59 & 28 \\
\hline Relative elongation, \% & 400 & 450 \\
\hline ShA hardness & 95 & 90 \\
\hline Tear resistance, $\mathrm{kN} / \mathrm{m}$ & 98 & 87 \\
\hline Stress at elongation by 300\%, MPa & 30 & 15 \\
\hline
\end{tabular}

Table 2. Mechanical characteristics of repair mixtures.

\begin{tabular}{|l|c|c|c|}
\hline \multirow{2}{*}{ Repair mixtures characteristics } & \multicolumn{3}{|c|}{ Repair mixture } \\
\cline { 2 - 4 } & Diagum FL & Diagum P & Diaflex \\
\hline Tensile strength at break, MPa & 40 & 38 & 30 \\
\hline Relative elongation, $\%$ & $500 \ldots 600$ & $400 \ldots 500$ & $400 \ldots 500$ \\
\hline Modulus of elasticity, MPa & $300 \ldots 350$ & $200 \ldots 300$ & $150 \ldots 200$ \\
\hline Temperature range of application, ${ }^{\circ} \mathrm{C}$ & $-40 \ldots+120$ & $-40 \ldots+120$ & $-40 \ldots+120$ \\
\hline
\end{tabular}

Early experimental studies of connecting rubber with steel surfaces showed that adhesion of all repair mixtures to elastomers is very high. Strength of glue layer was higher than rubber strength. Adhesion of repair mixtures to metals is much worse, but at the same time, strength 
of such connection is several times higher than strength of known glues for cold connecting $[21,22]$.

Further studies were focused on improvement of adhesion of glues to steel surfaces. Device for experimental studies was manufactured. It makes glue layer to be working in shear direction (refer to Fig. 1). These studies were carried out on laboratory machine ИМ-4A (refer to Fig. 2). Samples before being glued are shown on Fig. 3.

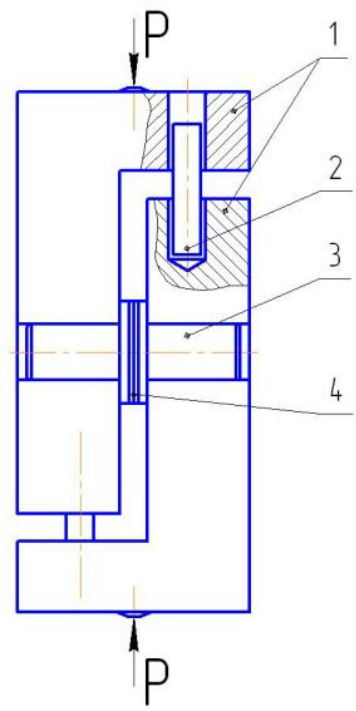

Fig. 1. Device for experimental studies of glue layer strength: pos. 1 is body; pos. 2 is pin; pos. 3 is sample; pos. 4 is layer of glue.

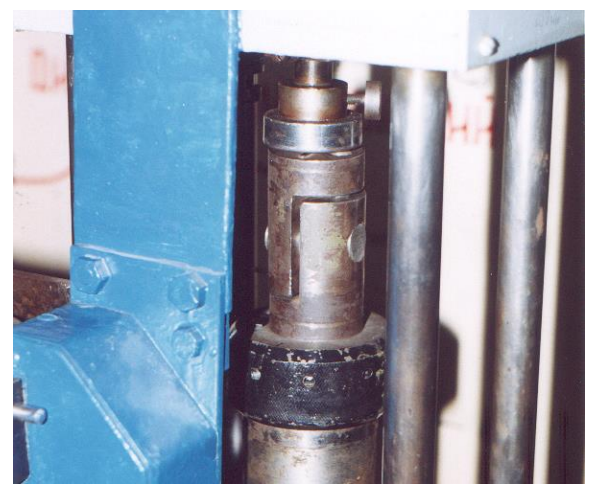

Fig. 2. Device installed in laboratory machine ИМ-4A.
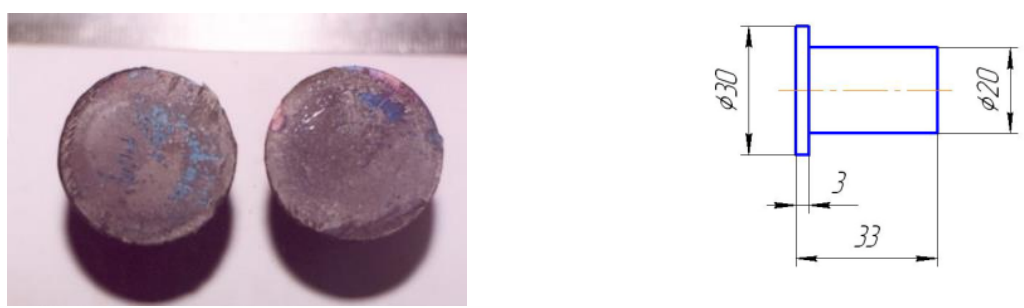

Fig. 3. Samples before being glued. 
Shear diagrams of layers made by repair mixtures Diagum FL, Diagum P and Diaflex are shown on Fig. 4 a, b and c. Thus, layer of particular repair mixture made glued connection of two metal samples. Thickness of the layer was $0.2 \ldots 0.5 \mathrm{~mm}$; average value $\delta=0.35 \mathrm{~mm}$.

Samples surfaces to be glued were cleaned with abrasive paper and degreased. Thin layer of particular repair mixture was applied to the surfaces to be glued; samples were connected and placed in a vertical position. Excess glue was squeezed out by weight of top sample beyond glued surface where it was mechanically removed.

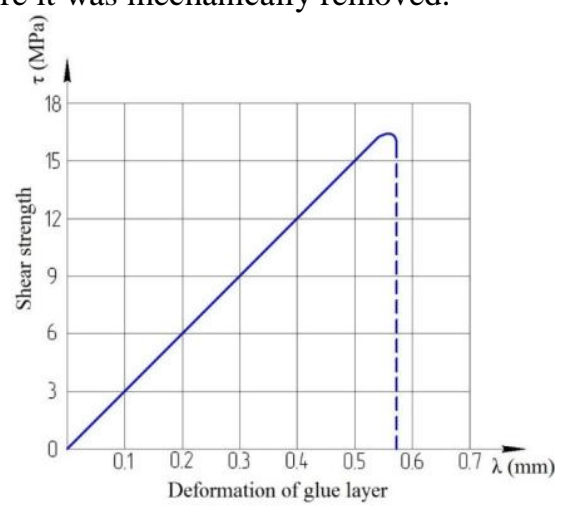

a

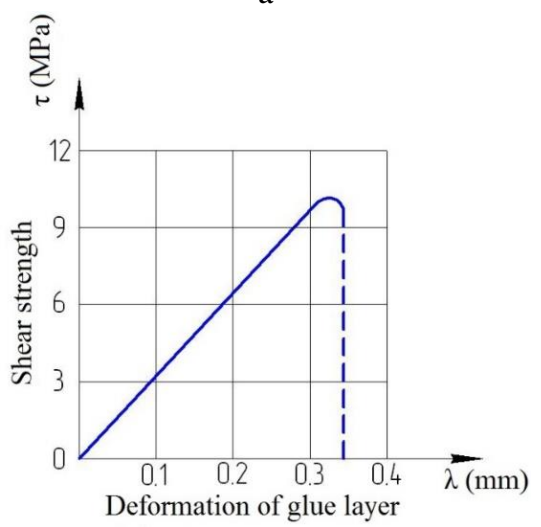

$\mathrm{b}$

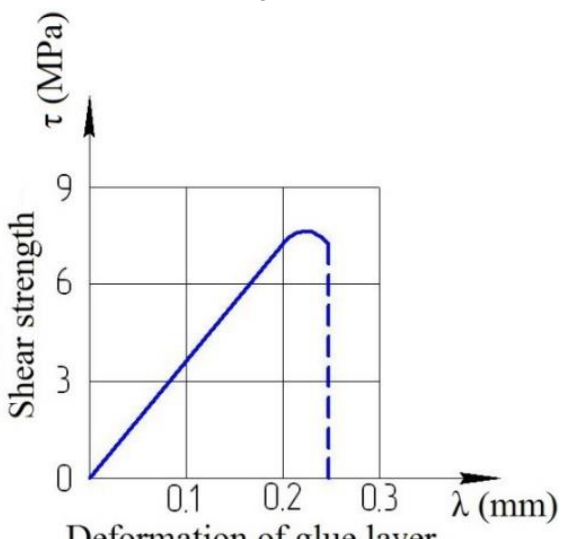

Deformation of glue layer

c

Fig. 4. Shear diagrams of layers made by repair mixtures: a is Diagum FL; b is Diagum P; $c$ is Diaflex. 
Drying of the samples was carried out at different temperatures: $\mathrm{t}_{1}=20^{\circ} \mathrm{C}, \mathrm{t}_{2}=40^{\circ} \mathrm{C}$ and $\mathrm{t}_{3}=60^{\circ} \mathrm{C}$. Strength of the samples glued connection increases over time, it can be described by exponential dependency:

$$
\tau_{\mathrm{t}}=\tau^{*}\left(1-\mathrm{e}^{-\frac{\mathrm{m}}{\mathrm{T}}}\right),
$$

where $\tau_{\mathrm{m}}$ is strength of the connection after aging for $\mathrm{m}$ hours;

$\tau^{*}$ is strength of the connection after long aging (more than 30 days);

$\mathrm{T}$ is constant of time that depends on aging of glue layer.

When aging is done at:

- $\mathrm{t}_{1}=20^{\circ} \mathrm{C} \mathrm{T} \approx 100 \ldots 120 \mathrm{hrs}$;

- $\mathrm{t}_{2}=40^{\circ} \mathrm{C} \mathrm{T}=15 \ldots .20 \mathrm{hrs}$;

- $\mathrm{t}_{3}=60^{\circ} \mathrm{C} \mathrm{T}=8 \ldots 10 \mathrm{hrs}$.

To obtain calculated strength of $95 . .98 \%$ of the maximum one it needs time $t=3 \mathrm{~T}$...4T. Graph of increase of glued connection strength over time is shown on Fig. 5. On practice, total polymerization time (i.e., to achieve maximum strength) can be considered as time equal to $3 \mathrm{~T}$.

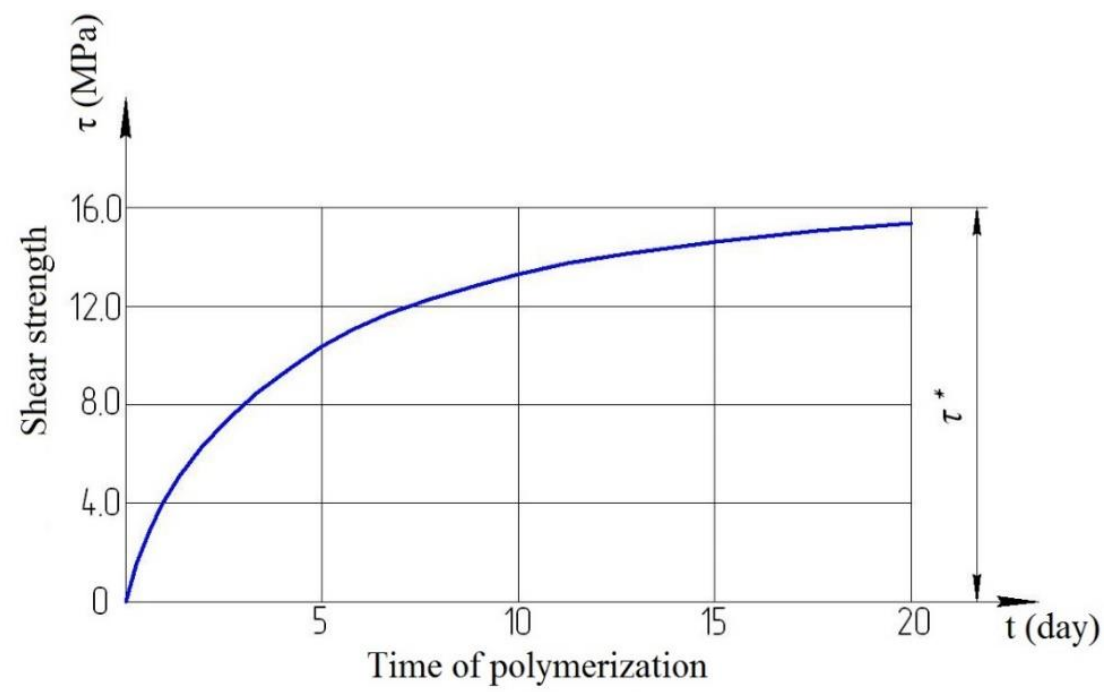

Fig. 5. Change of glue layer strength.

Results of the experimental studies are summarized in Table 3. The biggest strength for connection of the metal samples does Diagum FL. Results of statistical processing as per method [6] of the experimental studies are summarized in Table 4.

Table 3. Strength of glue connection.

\begin{tabular}{|c|c|c|c|c|}
\hline \multirow{2}{*}{$\begin{array}{l}\text { No. of } \\
\text { sample }\end{array}$} & \multicolumn{3}{|c|}{ Shear strength (MPa) } & \multirow{2}{*}{ Notes } \\
\hline & Diagum FL & Diagum $P$ & Diaflex & \\
\hline 1 & 14.1 & 7.1 & 6.1 & \multirow{6}{*}{$\begin{array}{l}\text { Samples were kept at } \\
\text { temperature of } 20^{\circ} \mathrm{C} \\
\text { for } 30 \text { days or at } \\
\mathrm{t}=40^{\circ} \mathrm{C} \text { for } 6 \text { days or at } \\
\mathrm{t}=60^{\circ} \mathrm{C} \text { for } 2 \text { days. } \\
\text { During that time }\end{array}$} \\
\hline 2 & 17.2 & 8.2 & 6.3 & \\
\hline 3 & 15.5 & 7.2 & 6.7 & \\
\hline 4 & 15.7 & 7.7 & 6.7 & \\
\hline 5 & 14.9 & 7.8 & 6.8 & \\
\hline 6 & 15.2 & 8.0 & 6.2 & \\
\hline
\end{tabular}




\begin{tabular}{|c|c|c|c|c|}
\hline 7 & 12.8 & 7.6 & 6.5 & \multirow{24}{*}{$\begin{array}{l}\text { polymerization of glue } \\
\text { layer had been almost } \\
\text { completed }\end{array}$} \\
\hline 8 & 13.9 & 8.2 & 6.5 & \\
\hline 9 & 14.9 & 7.4 & 6.6 & \\
\hline 10 & 16.1 & 7.9 & 6.8 & \\
\hline 11 & 16.2 & 7.4 & 6.3 & \\
\hline 12 & 15.6 & 8.0 & 6.0 & \\
\hline 13 & 15.5 & 7.7 & 6.9 & \\
\hline 14 & 15.9 & 7.7 & 7.0 & \\
\hline 15 & 15.0 & 7.5 & 7.1 & \\
\hline 16 & 15.8 & 7.9 & 6.6 & \\
\hline 17 & 16.0 & 7.7 & 6.7 & \\
\hline 18 & 16.1 & 7.8 & 6.5 & \\
\hline 19 & 15.8 & 8.1 & 6.5 & \\
\hline 20 & 15.3 & 7.4 & 7.0 & \\
\hline 21 & 15.4 & 7.6 & 6.4 & \\
\hline 22 & 16.4 & 7.8 & 6.6 & \\
\hline 23 & 16.3 & 7.9 & 6.8 & \\
\hline 24 & 15.2 & 7.7 & 6.8 & \\
\hline 25 & 15.3 & 7.8 & 6.7 & \\
\hline 26 & 15.9 & 7.3 & 6.6 & \\
\hline 27 & 15.7 & 7.9 & 6.5 & \\
\hline 28 & 15.5 & 7.6 & 6.5 & \\
\hline 29 & 15.0 & 7.7 & 6.4 & \\
\hline 30 & 15.4 & 7.7 & 6.6 & \\
\hline
\end{tabular}

Table 4. Results of statistical processing of the glues experimental studies.

\begin{tabular}{|c|c|c|c|}
\hline $\begin{array}{l}\text { Parameters of sample/ } \\
\text { Glue / repair mixture }\end{array}$ & Diagum FL & Diagum P & Diaflex \\
\hline $\begin{array}{l}\text { Complete sample n, metal } \\
\text { samples }\end{array}$ & 30 & 30 & 30 \\
\hline $\begin{array}{l}\text { Average value } \\
\bar{x}=\frac{\sum_{i=1}^{n} x_{i}}{n}\end{array}$ & 15.12 & 7.71 & 6.61 \\
\hline $\begin{array}{c}\text { Dispersion } \\
\mathrm{S}^{2}=\frac{1}{\mathrm{n}-1} \sum_{\mathrm{i}=1}^{\mathrm{n}}\left(\mathrm{x}_{\mathrm{i}}-\overline{\mathrm{x}}\right)^{2}\end{array}$ & 0.792 & 0.074 & 0.070 \\
\hline $\begin{array}{l}\text { Standard deviation } \\
\mathrm{S}=\sqrt{\mathrm{S}^{2}}\end{array}$ & 0.8899 & 0.2721 & 0.2647 \\
\hline $\begin{array}{l}\text { Coefficient of variation } \\
v=\frac{\mathrm{S}}{\mathrm{x}} \cdot 100 \%\end{array}$ & 0.0589 & 0.0353 & 0.040 \\
\hline $\begin{array}{l}\text { Number of degrees of freedom } \\
\qquad \mathrm{k}=\mathrm{n}-1\end{array}$ & \multicolumn{3}{|c|}{29} \\
\hline Confidence interval & \multicolumn{3}{|c|}{0.9} \\
\hline Student's t-test, $\mathrm{t}_{\alpha, \mathrm{k}}$ & \multicolumn{3}{|c|}{1.699} \\
\hline $\begin{array}{c}\text { Confidence interval of } \\
\text { average value }\end{array}$ & $14.844<\mathrm{a}<15.996$ & $7.626<a<7.794$ & $6.528<a<6.692$ \\
\hline
\end{tabular}




\section{Conclusions}

1. For the most durable elastomers (e.g. polyurethane Adiprene L-167 and Adiprene L-100) it is more useful to use repair mixture / glue that provides the greatest strength i.e. Diagum FL. For other elastomers (rubbers based on natural and synthetic rubbers) Diagum P or Diaflex can be used which provide strength of the connection at level of strength of glued rubber. At the same time, they are much cheaper than Diagum FL.

2. Obtained results provide development of durable and economical technical solutions: shear shock absorbers, elastic couplings, elastic shafts with high energy intensity which in some cases allow to avoid failures of metallurgical equipment under dynamic loading. In addition, use of repair mixtures with elastomers helps to make durable coatings of steel surfaces, e.g. coatings of riddle screens in blast furnaces.

\section{Acknowledgments}

The reported study was funded by RFBR according to the research project №19-08-01241a 'Multilevel modelling of deformation, filtration and fracture of oil-and-gas geological environments'.

\section{References}

1. N.S. Gharaibeh, M.I. Matarneh, V.G. Artyukh, Research Journal of Applied Sciences, Engineering and Technology 8(12), 1461-1464 (2014)

2. V. Mazur, V. Artyukh, G. Artyukh, M. Takadzhi, Engineering Designer 37(1), 26-29 (2012)

3. M.I. Matarneh, N.S. Gharaibeh, V.G. Artyukh, International Journal of Engineering Science and Innovative Technology (IJESIT) 4(2), 1-7 (2015)

4. V.V. Kukhar, O.V. Vasylevskyi, Metallurgical and Mining Industry 3, 71-78 (2014)

5. V. Kukhar, V. Artiukh, A. Butyrin, A. Prysiazhnyi, Advances in Intelligent Systems and Computing, Springer, Cham 692, 201-211 (2018) DOI: https://doi.org/10.1007/978-3-319-70987-1_22

6. V. Artiukh, T. Raimberdiyev, V. Mazur, MATEC Web of Conferences 53, 01039 (2016) DOI: http://dx.doi.org/10.1051/matecconf/20165301039

7. V. Artiukh, M. Belyaev, I. Ignatovich, N. Miloradova, IOP Conf. Series: Earth and Environmental Science 90, 012228 (2017) DOI:10.1088/1755-1315/90/1/012228

8. V. Artiukh, V. Mazur, S. Kargin, L. Zakharova, MATEC Web of Conferences 170, 03028 (2018) DOI: https://doi.org/10.1051/ matecconf/201817003028

9. S.N. Yakovlev, V.L. Mazurin, Magazine of Civil Engineering 6, 53-60 (2017) DOI: 10.18720/MCE.74.5

10. L.I. Ogorodov, Mechanics of Composite Materials 30(6), 771-780 (1994)

11. H. Zhang, Y. Chen, Y. Zhang, X. Sun, H. Ye, Journal of Elastomers and Plastics 40, 161-177 (2008)

12. J. Datta, Journal of Elastomers and Plastics 42, 117-127 (2010)

13. C. Miehe, J. Keck, J. Mech. Phys. Solids 48, 323-365 (2000)

14. Z. Petrovic, J. Ferguson, Polyurethane Elastomers. Prog. Polym. Sci. 16, 695-836 (1991)

15. J.S. Bergstrom, M.C. Boyce, Large strain time-dependent behavior of filled elastomers. Mech. Mater. 32, 627-644 (2000)

16. J. Bergstrom, M.C. Boyce, Rubber Chem. Tech. 72, 633-656 (1999) 
17. E.G. Bajsic, V. Rek, A. Sendijarevic, V. Sendijarevic, K.C. Frisch, Journal of Elastomers and Plastics 32, 162-182 (2000)

18. F.M.F. Al-Quran, M.E. Matarneh, V.G. Artukh, Research Journal of Applied Sciences, Engineering and Technology 4(11), 1585-1589 (2012)

19. V.G. Artiukh, S.Yu. Karlushin, E.N. Sorochan, Procedia Engineering 117, 938-944 (2015) DOI: 10.1016/j.proeng.2015.08.180

20. A.A. Ishchenko, Metallurgical processes and equipment 1, 55-58 (2005)

21. I.A. Starostina, Glues. Sealants, Technologies 7, 27-30 (2012)

22. E.A. Galihanova, Synergy of sciences 6, 515-521 (2016) 